\title{
Motivação, lógica e psicologia \\ explicativa em Edmund Husserl
}

Motivation, logic and explanatory psychology in Edmund Husserl

DOI: http://dx.doi.org/10.12957/ek.2015.16164

Prof. Dr. Savio Passafaro Peres

savioperes@yahoo.com.br

PUC-SP | FAPESP

Em Ideias II (1912), Husserl aborda pela primeira vez de forma detalhada o problema da motivação. Para ele, a motivação é lei fundamental do mundo espiritual. Apesar da importância que o tema da motivação joga em seu pensamento, a literatura especializada nem sempre tem dado a devida atenção a ele. $\mathrm{O}$ objetivo deste trabalho é elucidar os problemas lógicos que conduziram Husserl a introduzir em seu sistema o conceito de motivação. Pretendemos mostrar como a introdução do conceito de motivação possui importantes implicações para o conceito de psicologia de Husserl, particularmente para a distinção que ele realizava, em Investigações Lógicas, entre psicologia descritiva e psicologia explicativa.

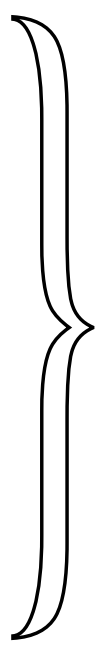

PALAVRAS ChAVE psicologia fenomenológica . motivação . Edmund Husserl

In Ideas II (1912), Husserl addresses for the first time in detail the problem of motivation. For him, the motivation is the fundamental law of the spiritual world. Despite the importance that the issue of motivation plays in his thought, the literature has not always given proper attention to it. The objective of this study is to elucidate the logical problems that led Husserl to introduce in his system the concept of motivation. We intend to show how the introduction of the concept of motivation has important implications for the concept of Husserl's psychology, particularly for the distinction he performed in Logical Investigations, between descriptive psychology and explanatory psychology.

KEYWORDS phenomenological psychology . motivation . Edmund Husserl 


\section{Introdução: A Psicologia e a filosofia na virada para o século XX na Alemanha}

O contexto da psicologia no período que compreende a produção de Husserl é altamente complexo, constando de várias propostas concorrentes, além de um intenso debate concernente tanto aos métodos e ao objeto da psicologia, quanto à sua relação com a filosofia. A psicologia, durante esse período, buscava-se firmar como ciência e, para isso, ela deveria de algum modo estabelecer seus limites e sua relação com a filosofia (Kusch, 1995). Neste processo, encontramos uma série de tentativas de se traçar a relação entre psicologia, ciências naturais e filosofia.

Um dos pontos mais controversos desse debate dizia respeito aos fenômenos volitivos. Se a ciência natural parte do pressuposto de que tudo o que acontece tem uma causa natural, como explicar a vontade? Teria ela uma causa? Mas, afirmar que ela é determinada causalmente não implica em rejeitar a liberdade e, consequentemente, a responsabilidade moral dos homens pelos seus atos? A principal dificuldade era a de se integrar em uma visão determinística da natureza, pressuposta pelas ciências naturais, a concepção de que o homem é um ser racional, responsável pelos seus atos. Muitos autores da época buscaram enfrentar tais problemas, os quais exigiam articular os conceitos de causalidade psíquica, motivação e liberdade ${ }^{1}$.

A complexidade deste debate ocorre não só pela diversidade de posições, mas também pelo fato de ele possuir um intricado desenvolvimento, uma vez que muitos dos psicólogos e filósofos foram modificando, refinando e aprofundando suas concepções ao longo dos anos e, não raro, em meio a polêmicas. Isso ocorre visivelmente em autores da estatura de Wundt, Husserl, Brentano, Dilthey, Pfänder, apenas para citar alguns poucos exemplos. No caso específico de Husserl, o problema da causalidade e motivação vai ocupando gradativamente a sua atenção logo após a escrita de Investigações Lógicas (1900/1901). Contudo, é apenas em 1912, em Ideias II, que Husserl dá um tratamento mais pormenorizado a esse problema. São várias as razões que o conduzem a se ocupar, cada vez mais,

$1 \mathrm{~A}$ esse respeito, Wundt apresenta concepções que foram bastante influentes em seu tempo. Já em 1863, Wundt havia distinguido entre causalidade e motivação. Embora a vontade não estivesse submetida à causalidade natural como era o caso dos instintos, ela não seria arbitrária, mas seria motivada. $\mathrm{O}$ característico da relação motivacional seria a ausência de necessidade entre os termos da relação. Em uma obra posterior, Grundriss der Psychologie, Wundt iria definir sua psicologia como voluntarismo. Uma posição diferente desta, e que iria influenciar o jovem Husserl, encontramos em Brentano. Em sua obra de 1874, Brentano (1874) havia definido a psicologia como o estudo dos atos psíquicos (inclusive os atos volitivos), os quais estariam determinados por leis naturais, e, portanto, poderiam, a princípio, ser explicados causalmente pelo método das ciências naturais. 
do tema da motivação e da causalidade psíquica. De acordo com Boer (1978) e outros autores, o tema da motivação encontra-se estreitamente vinculado ao desenvolvimento de dois temas (1) a virada transcendental da filosofia husserliana, que ocorre por volta de 1906/1907, (2) concepção de psicologia eidética tomada como ontologia regional da alma (Seele), que Husserl passa a desenvolver a partir de 1912. O desenvolvimento destes dois temas levou Husserl a desafiar alguns dos dogmas implicados nas ciências naturais. Ou seja, o desenvolvimento da motivação encontra-se fortemente associado com a crítica ao naturalismo, crítica essa que Husserl passa a realizar de forma mais enfática a partir de 1911, como se observa em Filosofia como ciência de rigor (1965/1911).

Podemos dizer que a tese de que as leis da motivação são leis essenciais da consciência humana (Husserl, 1912/1952, p.211) cumpre um papel decisivo na resolução de dois problemas que Husserl apenas se deu conta após Investigações Lógicas (1900/1901):

O primeiro diz respeito à tensão, presente em Investigações Lógicas, concernente à ontologia pressuposta pelo platonismo husserliano e à ontologia pressuposta pelas ciências naturais. Isto estaria correlacionado à crítica que Husserl começa a fazer, a partir de 1911, da naturalização da consciência.

$\mathrm{O}$ segundo diz respeito à relação entre psicologia descritiva e psicologia explicativa. Em Investigações Lógicas, Husserl entende que a fenomenologia teria não só a função de fundamentar epistemologicamente a lógica pura, mas também a função de preparar a base conceitual para a realização da psicologia explicativa, a qual ele entende, em 1901, que deveria ser realizada como ciência natural. Ou seja, em 1901, Husserl identifica a psicologia explicativa com psicologia natural-causal.

Contudo, nos anos subsequentes à publicação de Investigações Lógicas, Husserl passa a entender que a psicologia, tomada como ciência natural, era insuficiente para explicar causalmente a vida intencional. A fim de se compreender as ações e as vivências da pessoa humana, é necessário levar em consideração uma nova forma de causalidade não redutível ao conceito de causa natural, ou seja, a causa motivacional. Tal forma de causalidade era imprescindível para compreender (1) as conexões entre as vivências lógicas e (2) as relações entre as vivências intencionais e o mundo circundante (Umwelt). Para compreender a relação entre as vivências, é preciso levar em consideração não só as propriedades físicas dos objetos, mas também os sentidos com os quais os diferentes objetos do mundo (incluindo os objetos culturais) se apresentam para o sujeito e para uma comunidade de sujeitos. Neste artigo irei me focar no problema concernente entre a motivação e as conexões entre as vivências lógicas. 


\section{Psicologia descritiva e psicologia explicativa}

Uma das distinções mais importantes realizadas por Husserl logo no início do segundo volume de Investigações Lógicas é entre "psicologia descritiva" e "psicologia explicativa". A esta última Husserl também se refere pelas expressões: "psicologia genética", "psicologia empírica", "psicologia causal". Ao distinguir entre essas duas formas de psicologia Husserl não faz mais do que resgatar uma concepção de seu mestre Brentano ${ }^{2}$, o qual distinguia entre psicognose e psicogenética, as quais diferem não pelo objeto (atos psíquicos), mas pelo método. O escopo da primeira é "a determinação exaustiva (se possível) dos elementos da consciência humana e das formas pelas quais eles estão conectados" (Brentano, 1889/2002, p.3). Já a psicologia genética visa "a descrição das condições causais a que os fenômenos particulares estão sujeitos". (Brentano, 1889/2002, p.3).

Em Investigações Lógicas Husserl praticamente replica a distinção de Brentano. Para Husserl, a psicologia empírica é uma ciência natural explicativa. O princípio que a rege pode ser expresso do seguinte modo: “(...) o que acontece sobre determinados grupos de circunstâncias acontece necessariamente, isto é, de acordo com as leis da natureza." (Husserl, 1901/1984a, p.26). O pressuposto subjacente é que um fato natural não ocorre de maneira fortuita, mas sim porque determinados grupos de circunstâncias reais ocorreram.

A psicologia empírica é uma entre várias outras ciências explicativas. Cada ciência explicativa deve delimitar adequadamente o seu domínio de fatos. $\mathrm{Na}$ quinta Investigação lógica, Husserl afirma que, no caso da psicologia, os fatos que constituem o seu campo são as vivências.

Para Husserl, vivências são ocorrências ou processos conscientes. Podemos falar das vivências de pensar, vivências de se lembrar, vivências de medo, de esperança, vivências de imaginar, etc. Enquanto estamos conscientes, estamos tendo vivências. As vivências se sucedem e se entremeiam umas nas outras. Neste instante, tenho vivências de pensar, de ler, de escutar os sons da rua, de sentir meus pés, meu corpo, etc. As vivências, portanto, são os constituintes do fluxo de consciência. Por essa razão, já no início da quinta Investigação,

2 A obra mais conhecida de Brentano é Psicologia do ponto de vista empírico. A importância desta obra se dá devido à sua apropriação do conceito escolástico de intencionalidade. Sabemos que essa obra exerceu profunda influência em Husserl (Fisette, 2010). Contudo, Husserl não foi influenciado apenas pelas ideias que estão presentes nesta obra. Se quisermos compreender as ideias que mais tiveram influência em Husserl devemos recorrer ao conteúdo presente em outra obra de Brentano, Psicologia Descritiva (Deskriptive Psychologie). Trata-se obra póstuma que reúne os manuscritos da segunda metade da década de 1880. 
Husserl alerta que existe uma maneira não técnica de se falar de vivências, a qual não é o sentido que ele pretende. Não há, por exemplo, uma vivência na sala de aula, ou vivência da guerra. O que há é que, durante o momento em que a pessoa esteve na guerra, ela teve várias vivências, por exemplo, medo, raiva, sensação de dor, de fome, vivências de esperança, etc.

Em Investigações Lógicas Husserl considera que as vivências são ocorrências reais (Husserl, 1901/1984a, pp.357, 401-402). Essa concepção de vivência como "fato real" ou "ocorrência real" não pode ser menosprezada. É comum atualmente a concepção de que a consciência é um mero epifenômeno sem positividade e sem realidade. Este não é o caso em Investigações Lógicas. Aí vivências são tomadas não só como processos reais, como também naturais. Assim como qualquer processo natural, as vivências surgem, duram determinado intervalo de tempo, afetam e são afetadas e desaparecem. A caracterização das vivências como processos reais naturais carrega consigo um conjunto de importantes consequências para o problema da causalidade psíquica, consequências essas as quais Husserl, durante a escrita de Investigações Lógicas, não foi capaz de perceber (Husserl, 1911/1965, pp.9-13). A fim de entendermos essas consequências, é preciso compreender o que, em Investigações Lógicas, Husserl entende ser uma entidade real. De acordo com ele (1901/1984a, p.129), todo ser real:

1. É marcado pela temporalidade (Sphäre der Zeitlichkeit). Ou seja, tudo o que ocorre realmente deve ter um início, uma duração e um fim.

2. É sempre singular e irrepetível.

3. É parte da totalidade causal do universo. Todo ser real se relaciona com outros entes reais.

4. Os modos de relações entre as entidades reais são passíveis, a princípio, de serem exploradas pelo método natural. $\mathrm{O}$ método natural pressupõe a existência de uma regularidade no universo. Objetos semelhantes comportam-se de maneira semelhante em circunstâncias semelhantes. Em suma, Husserl identifica implicitamente o ser real e o ser natural (Zahavi, 2003).

Tomemos, como exemplo, essa cadeira de madeira que estou sentado. Em primeiro lugar, trata-se de uma cadeira que tem uma origem, que durará um determinado tempo e deixará de existir. Em segundo lugar, nenhuma outra 
cadeira será absolutamente igual a ela. Em terceiro lugar, ela não é algo separado no mundo, mas pertence ao mundo. Em quarto lugar, ela possui uma multiplicidade de relações causais com outros objetos reais: se a colocarmos em uma superfície muito irregular, ela cairá ao chão, se a colocarmos no fogo, ela pegará fogo, etc.

Agora apliquemos tais determinações do conceito de realidade ao conceito de vivência. Assim como um fato nunca se repete, também uma vivência nunca se repete. Cada homem vivente é algo real bem como todas as partes que o constituem, razão pela qual Husserl, em Investigações Lógicas afirma que as vivências constituem a "consciência do respectivo indivíduo psicofísico." (Husserl, 1901/1984a, pp.357). Se o homem, em sua totalidade, é um ser natural, também suas vivências têm causas naturais. Em alguns casos, isso é fácil constatar. Uma martelada em minha mão causa em mim uma vivência de dor. Ou seja, há uma relação de causalidade natural entre a martelada e a dor. Mas se todas as vivências estão sujeitas à causalidade natural, não só sentimentos e sensações têm causas naturais, mas também vivências lógicas. É aí, como veremos, onde reside o problema.

\section{Psicologia e lógica}

Observemos agora essa última classe de vivências, as vivências lógicas, e examinemos as implicações de tomá-las como reais. Para compreendermos tais implicações, é necessário observar uma nova distinção que Husserl realiza entre psicologia e lógica pura e, correlativamente, entre conteúdo real e conteúdo lógico-ideal de uma vivência.

Suponhamos que um lógico esteja demonstrando um teorema a partir de axiomas. Neste caso, podemos dizer que o lógico está tendo vivências lógicas, conectando seus julgamentos de maneira racional. Ora, do ponto de vista real-psicológico (e não lógico), um raciocínio demonstrativo consiste em uma série de eventos mentais (vivências judicativas lógicas) que ocorre na consciência de um ser humano real. Mas, do ponto de vista lógico, uma demonstração não é um conjunto de vivências psíquicas. O que é então? Trata-se, afirma Husserl, de uma estrutura objetiva lógica-ideal, a qual pode ser expressa em signos linguísticos. Um silogismo "Todo homem é mortal”, "Sócrates é homem", logo "Sócrates é mortal", é, do ponto de vista lógico, um conjunto de três proposições ideais conectadas entre si por uma forma lógica. O silogismo 
não é um conjunto de vivências, mas uma estrutura lógica possível. Várias pessoas podem ter acesso e compreender o mesmo silogismo. Uma pessoa pode voltar ao mesmo silogismo quantas vezes quiser, mas ela não pode voltar e reviver de maneira originária uma vivência que já passou. Em suma, duas pessoas podem ter acesso à mesma entidade lógica. E isso não significa que elas tenham exatamente as mesmas vivências.

De acordo com Husserl (1900/1975, p.178), um dos problemas mais sérios realizados pela tradição, e que teve graves consequências para a lógica, filosófica foi a não percepção de que há uma ambiguidade em termos como "juízo", "significação", "asserção", "raciocínio", etc. O problema é que tais expressões, do ponto de vista lógico, designam estruturas lógicas, mas do ponto de vista psicológico designam determinados tipos de vivências. Há uma diferença entre a vivência de julgar que Brasília é a capital do Brasil e o próprio juízo expresso no enunciado "Brasília é a capital do Brasil". Se eu digo a uma pessoa que Brasília é a capital do Brasil e essa pessoa me entende, nós compartilhamos o mesmo conteúdo ideal, mas não a vivência de julgar, pois esta última, como já foi exposto, é um evento real, e, portanto, privado e irrepetível. Mas é claro que, embora tenhamos que diferenciar a vivência de julgar do juízo em sentido lógico, há uma relação estreita entre ambos, pois é na vivência de julgar que um juízo, em sentido lógico, é expresso. A fim de dar conta desta situação, Husserl distingue dois tipos de conteúdos em uma vivência lógica, o conteúdo real e o conteúdo lógico-ideal (1901/1984b, p.57). Ora, é justamente esse conteúdo ideal que pode ser compartilhado e não o conteúdo real, pois já sabemos que o conteúdo real é sempre singular e jamais se repete 3 .

A lógica pura não se preocupa com o juízo enquanto vivência psíquica, mas sim com o conteúdo ideal objetivo da vivência de julgar. Para Husserl, o psicologismo lógico é resultado de não se perceber a diferença entre o conteúdo ideal e o conteúdo real de uma vivência, de modo que o primeiro acaba sendo reduzido ao segundo.

Até o momento caracterizamos os entes reais e observamos algumas implicações de se considerar uma vivência algo real. Agora temos que caracterizar de maneira mais precisa o conteúdo ideal. O ideal contrapõe-se ao real (1901/1984a, pp.129-131). O ideal não está sujeito ao tempo, à causalidade e não ocupa lugar no espaço. Um teorema, por exemplo, não é algo que envelhece e que pode ser medido em qualquer unidade métrica. $\mathrm{O}$ que ocupa lugar

3 Para uma discussão mais detalhada sobre o problema do conteúdo em Investigações Lógicas, ver Boehm (1968). 
no espaço é sua expressão sensível. Sua expressão sensível é algo real, mas o sentido expresso pela expressão é ideal. Posso fazer um cartaz gigante com o teorema e posso escrever o mesmo teorema de maneira minúscula no caderno. Não temos dois teoremas de tamanhos distintos, mas sim duas expressões de tamanhos distintos de um mesmo teorema. Assim como um teorema é algo ideal, também uma proposição, um significado, uma teoria, uma demonstração, etc.

Levando-se em consideração o que foi exposto anteriormente, entende-se por que Husserl, em Prolegômenos, defende que o objeto de estudo da lógica não é nem o mundo físico nem o mundo psíquico, mas o mundo das idealidades. Com isso, Husserl se compromete com uma forma de platonismo lógico ${ }^{4}$. A lógica pura estuda as estruturas formais de uma teoria. Ela é, portanto, uma teoria que tem como objeto a estrutura de uma teoria. Ao colocar a lógica como uma ciência teórica, Husserl dá uma interessante resposta a um problema bastante discutido no fim do século XIX. É a lógica uma ciência teórica, normativa ou técnica (1900/1975, pp.22-23)? Ou seja, Husserl distingue três concepções conflitantes de lógica:

1) lógica como ciência teórica de estruturas, objetos e leis ideais, a qual investiga as condições de possibilidade objetivas de uma teoria (por exemplo, o princípio de contradição);

2) lógica como ciência normativa das vivências lógicas, a qual busca estabelecer as normas do pensar correto;

3) lógica como técnica ou arte (Kunst), a qual fornece procedimentos práticos para se pensar em conformidade com certas regras (ex.: derivar teoremas a partir de axiomas).

Sabemos que Husserl defende que a lógica é, acima de tudo, uma ciência teórica, que busca alcançar conhecimento das leis e princípios pertencentes às estruturas ideais. Mas se a lógica é uma ciência teórica, deveríamos descartar a lógica como norma e como técnica? A resposta de Husserl é um claro não. Embora a lógica como teoria seja o conceito mais fundamental, os dois outros conceitos também possuem o seu lugar. O ponto é que há uma relação necessária entre as três concepções de lógica (1900/1975, p.35). Das leis lógicas em sentido ideal é possível derivar as leis normativas, com as quais é possível avaliar se um raciocínio factual é válido ou inválido. A partir da lógica como

$4 \mathrm{O}$ qual deve ser distinguido do platonismo metafísico (Zahavi, 2003). 
ciência normativa, é possível desenvolver técnicas para colocar o pensar factual de acordo com as normas ${ }^{5}$. Ou seja, a lógica pura é o fundamento tanto da lógica normativa quanto da lógica tomada como técnica.

Mas se Husserl distingue lógica pura, como ciência de estruturas ideais, e psicologia, como ciência de vivências, qual a relação entre ambas? A resposta é: o projeto de Investigações Lógicas pode ser entendido como uma tentativa de se construir, com o auxílio da psicologia descritiva (ou fenomenologia), uma teoria da subjetividade compatível com o platonismo lógico. A fenomenologia, tomada como psicologia descritiva dedicada à análise das partes e momentos reais de uma vivência, seria capaz de explicitar as relações entre a vivência e os conteúdos ideais (1901/1984a, pp.22-24).

O problema é que Husserl, ao realizar tal projeto, acaba se comprometendo com duas concepções ontológicas. No momento em que ele assume que vivências são processos naturais e que a psicologia descritiva (fenomenologia) não tem maiores consequências para a psicologia genética, ele se compromete com uma visão de mundo naturalista. Husserl, apesar de sua alegada neutralidade metafísica, ao conceder a validade da psicologia natural-explicativa, ele acaba concedendo a validade da ontologia que a sustenta (Zahavi, 2002), ou seja, o naturalismo. Por outro lado, ao adotar a concepção de que vivências lógicas possuem conteúdos ideais, Husserl compromete-se com uma ontologia platônica. A pergunta que devemos colocar é: essas duas ontologias são compatíveis? Ao que parece, Husserl, em Investigações Lógicas, consegue apenas parcialmente compatibilizá-las. O problema é que ele compatibiliza a lógica pura com a psicologia descritiva, a partir de uma perspectiva estática. Como bem nota Sokolowski (1970) Husserl limita-se a mostrar onde a idealidade localiza-se na vivência. Ou seja, em Investigações Lógicas ele se limita a classificar as vivências e analisá-las, como um anatomista do espírito. Mas assim como um anatomista, ele não estuda o comportamento e o movimento de seu objeto de estudo. O problema encontra-se, sobretudo, quando Husserl começar a analisar a temporalidade da consciência, ou seja, as formas de conexões que ocorrem entre as vivências no fluxo. Neste momento, se revelará que a lógica como técnica não é plenamente compatível com a ontologia pressuposta pelo naturalismo.

A fim de compreendermos a incompatibilidade da lógica como técnica e a visão naturalista do mundo, uma comparação com a ética é bastante adequada.

5É importante, neste contexto, destacar a diferença entre lógica normativa e psicologia. A primeira diz como o pensamento deveria ser, a segunda como o pensamento humano em sua factualidade é. 
Também a ética pode ser dividida em teoria, norma e técnica. A ética como teoria investigaria quais ações são boas. Uma vez que se conheça o que é o bem e quais as boas condutas, é possível agora criar normas para a conduta humana. A ética, como norma, diz como o ser humano deveria agir, mas não como ele efetivamente age. Quem estuda como o ser humano efetivamente age é a psicologia e não a ética normativa. Mas uma vez estabelecida as normas, é possível agora buscar estabelecer técnicas para se agir conforme as normas éticas. $\mathrm{Ou}$ seja, é preciso criar técnicas para que o ser humano consiga seguir as normas. $\mathrm{O}$ problema é que a criação de técnicas pressupõe uma concepção de psicologia. Por exemplo, para agir de acordo com as normas, procure evitar colocar-se circunstâncias tentadoras, pois a psicologia ensina que o homem é influenciado por sua circunstância imediata. O problema é que, embora a concepção técnica pressuponha a psicologia, ela não é compatível com qualquer psicologia. Isso porque o conceito de técnica pressupõe o esforço consciente regulado por um ideal. O mesmo vale na lógica.

Tendo em consideração as reflexões anteriores, podemos levantar agora duas perguntas. Uma de ordem ontológica e outra de ordem epistemológica.

1) O conceito de esforço consciente para se adequar a um ideal é compatível com o determinismo psíquico, de acordo com o qual toda vivência, lógica ou não, tem uma causa natural.

2) As explicações causais naturais são suficientes para explicar a gênese de todas as classes de vivências?

Após Investigações Lógicas, Husserl passa a entender que a possibilidade de esforço consciente para se alcançar um fim implica não apenas um conceito de razão teórica, mas também de razão prática. Ou seja, a dimensão prática da razão humana é irredutível às explicações naturais causais. É claro que essa irredutibilidade não significa aleatoriedade. Afirmar que a razão não é explicável por meio de causas naturais quer dizer apenas que há formas de conexões entre vivências que não podem ser explicadas apenas pelos aspectos reais das vivências. Ou seja, há todo um grupo de vivências intencionais cuja conexão temporal entre si pressupõe a existência dos conteúdos ideais. Ou seja, o modo de se comportar da consciência pressupõe levar em consideração entidades irreais. Como bem expõe Boer (1978), o problema pode ser enunciado na seguinte pergunta: "Como pode a consciência estar sujeita a normas ideais e, ao mesmo tempo, ser considerada como parte da natureza, sujeita a leis estritamente cau- 
sais?” (Boer, 1978, p.502). Ou seja, é necessário que a apreensão das leis ideais e das normas que delas derivam motive racionalmente o curso do pensamento. Se eu tenho a vivência de julgar que "Todo homem é mortal" e em seguida eu tenho a vivência de julgar que "Sócrates é homem", é de se esperar que eu terei a vivência de julgar que "Sócrates é mortal". As duas primeiras vivências, em função do conteúdo ideal, produziu em mim a vivência de julgar que "Sócrates é mortal". Eu sou capaz de perceber com evidência que eu devo julgar que "Sócrates é mortal". A vivência de conclusão surge do fato de eu ter visto que ela decorria necessariamente das premissas. Ou seja, a conclusão é produzida por uma "causa motivacional". Essa causa motivacional é o que é em função do conteúdo ideal das vivências. Ela é derivada de uma lei ideal apreendida, que se aplica ao conteúdo ideal objetivo das vivências.

A explicação naturalista não pode dar conta dessa situação (Boer, 1978, p.503). Isso por uma razão muito simples. O naturalismo só vê realidades e pressupõe que tudo o que é real explica-se por relações regulares entre realidades. Por essa razão, a causa motivacional lhe escapa.

\section{Discussão Final}

Ao longo deste artigo, esperamos ter apresentado como a introdução do conceito de motivação implicou na reelaboração da relação entre fenomenologia e ciências naturais. Em 1900, Husserl achava que o surgimento e o desaparecimento das vivências, bem como o modo como elas se sucedem umas às outras poderia ser suficientemente explicado por uma psicologia empírico-natural. Isso se colocava em concordância com sua concepção de que vivências são processos reais e processos reais são processos naturais. Posteriormente, em Ideias II, Husserl irá desvincular a ideia de que vivências são processos reais-naturais. Para a fenomenologia pura, vivências são irreais. Para a psicologia fenomenológica, vivências são reais, embora não sejam entidades naturais. $\mathrm{Ou}$ seja, há toda uma camada de vivências que não podem ser suficientemente explicadas geneticamente apenas apelando à causalidade natural. 
BOER, Theodorus de. The development of Husserl's thought. The Hague; Boston: Nijhoff, 1978.

BOEHM, R. R. Vom Gesichtspunkt der Phänomenologie. Den Haag: Nijhoff, 1968.

BRENTANO, F. C. Psychologie vom empirischen Standpunkt. Leipzig: Verlag von Duncker \& Humblot, 1874.

Descriptive Psychology (B. Müller, Trans.). New York: Routledge. 2002. (Original de 1889).

FISETTE, D. Descriptive Psychology and Natural Sciences: Husserl's early Criticism of Brentano. In C. Ierna, H. Jacobs \& F. Mattens (Eds.), Philosophy, Phenomenology, Sciences: Essays in Commemoration of Edmund Husserl (pp. 221-254). New York: Springer, 2010.

HUSSERL, E. Ideen zu einer reinen Phänomenologie und phänomenologischen Philosophie; Buch 2, Phänomenologische Untersuchungen zur Konstitution. Den Haag: Nijhoff, 1952.

. Philosophie als strenge Wissenschaft. Frankfurt a.M.: Klostermann, 1965 (Trabalho original publicado em 1911).

Logische Untersuchungen. Bd. 1 Prolegomena zur reinen Logik (Hua 18). (E. Holenstein Ed.). Den Haag: Martinus Nijhoff. 1975. (Trabalho original publicado em 1900).

.Logische Untersuchungen, Zweiter Band, erste Teil Untersuchungen zur Phänomenologie und Theorie der Erkenntnis. (Hua 19/1) (U. Panzer Ed.). The Hague: Nijhoff, 1984 a (Trabalho original publicado em 1901).

Logische Untersuchungen. zweiter Band. zweiter Teil. Untersuchungen zur Phänomenologie und Theorie der Erkenntnis. (Hua 19/2) (U. Panzer Ed.). The
Hague: Nijhoff. 1984b, (Trabalho original publicado em 1901).

.Investigações lógicas. Segundo Volume. Parte I, Investigações para a fenomenologia e a teoria do conhecimento (P. M. S. Alves \& C. A. Morujão, Trans. Vol. XIX/I). Lisboa: Forense, 2012

KOCKELMANS, J. J. Edmund Husserl's phenomenological psychology: a historico-critical study. Atlantic Highlands, N.J.: Humanities Press, 1978.

KUSCH, M.. Psychologism : a case study in the sociology of philosophical knowledge. London; New York: Routledge, 1995.

SOKOLOWSKI, R. The Formation of Husserl's Concept of Constitution: Springer, 1970.

WUNDT, W. M. Grundriss der Psychologie. Leipzig: W. Engelmann, 1896.

ZAHAVI, D. Metaphysical Neutrality in Logical Investigations. In D. Zahavi \& F. Stjernfelt (Eds.), One hundred years of phenomenology : Husserl's Logical investigations revisited. Dordrecht; Boston: Kluwer Academic Publishers, 2002.

.Husserl's phenomenology. Stanford, Calif.: Stanford University Press, 2003.

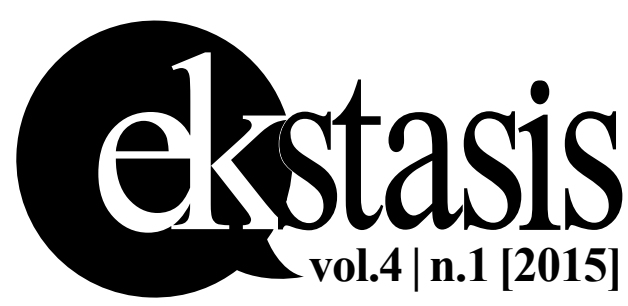

